\title{
CAMINHOS PARA A INOVAÇÃO NO CONTEXTO EDUCATIVO E ESCOLAR: O PAPEL DA MÍDIA-EDUCAÇÃO
}

\author{
CAMINOS PARA LA INNOVACIÓN EN EL CONTEXTO EDUCATIVO Y ESCOLAR: \\ EL PAPEL DE LA EDUCACIÓN DE MEDIOS
}

\section{PATHS TO INNOVATION IN THE EDUCATIONAL AND SCHOOL CONTEXT: THE ROLE OF MEDIA-EDUCATION}

\author{
Rosineide de Andrade ROCHA ${ }^{1}$ \\ Sílvio Henrique FISCARELLI ${ }^{2}$ \\ Rodolfo Augusto RODRIGUES ${ }^{3}$
}

RESUMO: A escola precisa atender às novas demandas da Era Digital. Para tanto, é necessário repensar e refazer novas relações com o saber, com a cultura, com o currículo escolar e com os alunos. Deve encarar o seu papel de mediar o acesso e a apropriação crítica e criativa dos meios midiáticos pelos estudantes, superando o modelo cartesiano e academicista de ensino e de aprendizagem e ajudando os sujeitos a transformarem o conhecimento em pensamento e sabedoria. É preciso, como postula a BNCC (Base Nacional Comum Curricular), explorar a mídia-educação, fomentando a permanência qualificada na escola para todos. Em suma, esse trabalho bibliográfico pretende investigar alguns caminhos para a inovação pedagógica, para a construção de uma escola com qualidade e relevância social para as novas gerações.

PALAVRAS-CHAVE: Inovação. Ensino-aprendizagem. Tecnologias da informação e comunicação. BNCC. Ensino fundamental.

RESUMEN: La escuela necesita atender las nuevas demandas de la Era Digital. Para ello, es necesario repensar y rehacer nuevas relaciones con el saber, con la cultura, con el currículo escolar y con los alumnos. Debe encarar su papel de mediar el acceso y la apropiación crítica y creativa de los medios mediáticos por los estudiantes, superando el modelo cartesiano y academicista de enseñanza y aprendizaje y ayudando a los sujetos a transformar el conocimiento en pensamiento y sabiduría. Es necesario, como postula la BNCC, explorar los medios de comunicación, fomentando la permanencia calificada en la escuela para todos. En resumen, ese trabajo bibliográfico pretende investigar algunos caminos para la innovación pedagógica a la construcción de una escuela con calidad y relevancia social para las nuevas generaciones.

PALABRAS CLAVE: Innovación en educación. enseñanza y el aprendizaje. tecnologías de la información y la comunicación. BNCC. enseñanza fundamental.

\footnotetext{
${ }^{1}$ Universidade Estadual Paulista - (UNESP), Araraquara - SP - Brasil. Mestranda em Educação Escolar. ORCID: https://orcid.org/0000-0003-1075-3164. E-mail: rosedeandraderocha@ hotmail.com.

${ }^{2}$ Universidade Estadual Paulista - (UNESP), Araraquara - SP - Brasil. Doutor em Educação Escolar. ORCID: https://orcid.org/0000-0001-9451-7198. E-mail: silvio.fiscarelli@unesp.br.

${ }^{3}$ Universidade Estadual Paulista - (UNESP), Araraquara - SP - Brasil. Mestrando em Educação Escolar. ORCID: https://orcid.org/0000-0003-4924-7293. E-mail: rodolfoaugusto2010@yahoo.com.br
} 
ABSTRACT: The school needs to meet the new demands of the Digital Age. Therefore, it is necessary to rethink and redo new relatiONS with knowledge, with culture, with the school curriculum and with students. It must face its role of mediating access and critical and creative appropriation of the media by students, overcoming the Cartesian and academic model of teaching and learning and helping subjects to transform knowledge into thought and wisdom. It is necessary, as the BNCC (Common National Curricular Base - Portuguese initials) postulates, to explore the media-education, promoting qualified permanence in school for all. In short, this bibliographic work intends to investigate some paths for pedagogical innovation, for the construction of a school with quality and social relevance for the new generations.

KEYWORDS: Innovation. Teaching-learning. Communication and information technologies. BNCC. Elementary School.

\section{Introdução}

A educação está em descompasso com as transformações socioculturais advindas da era do conhecimento e da informação. A celeridade e a volatilidade da vida moderna desafiam e abalam os paradigmas em que se assentavam as sociedades do passado; é preciso acertar o passo, recobrar os ânimos, consertar o ritmo - é preciso inovar. A escola precisa superar os paradigmas do modelo industrial, eivados de tradicionalismo e autoritarismo, para adentrar nesse novo milênio de forma renovada, recompondo-se, enfim, para fazer jus à sua função institucional: educar com qualidade e relevância social as novas gerações.

Acerca do contexto educacional brasileiro, alguns autores postulam que a crise não ocorre somente pela falta de recursos financeiros, mas sim, uma crise de sentidos diante da perplexidade e incerteza que dominam os horizontes da vida contemporânea; o notável avanço da ciência e da tecnologia não está sendo seguido de avanços no plano existencial e ético (MORIN; CIURANA; MOTTA, 2003). Assim, diante da arena da Era Planetária, as TIC's (Tecnologias da Informação e comunicação) são apresentadas como algo positivo e necessário para que se supere a ideia subdesenvolvida de desenvolvimento, em que a busca pelo progresso é posta em detrimento do bem-estar humano e social.

Diante disso, à instituição escolar impõe-se o desafio de galgar novas relações com o saber, superando o modelo cartesiano e academicista, do período em que foi concebida como instituição educativa de massa, no final do século XIX. Pérez Gómez (2015) salienta que a escola convencional se encontra demasiadamente distante das aspirações advindas da pesquisa e da inovação pedagógicas, sobretudo no terreno das práticas e das teorias em uso; isso indica que a práxis escolar, com poucas exceções, permanece em estado de inércia e de letargia. Indica também que, diante das demandas que se apresentam no novo plano mundial, as mudanças no 
cenário educacional e escolar são tímidas e pouco significativas: "A inovação educacional sempre é minoritária, marginal e efêmera" (p. 12). Como sublinha o autor,

O desafio da escola contemporânea reside na dificuldade e na necessidade de transformar a enxurrada desorganizada e fragmentada de informações em conhecimento, ou seja, em corpos organizados de proposições, modelos, esquemas e mapas mentais que ajudem a entender melhor a realidade, bem como na dificuldade para transformar esse conhecimento em pensamento e sabedoria (PÉREZ GÓMEZ, 2015, p. 28).

Para atender às novas exigências sociais, Bizelli (2009) postula que o direito à conexão com o ciberespaço é tão fundamental, nos dias atuais, quanto os direitos básicos à saúde, educação, segurança, seguridade social, etc. Afirma ainda que todos os cidadãos precisam ter acesso à rede, mas que esse acesso precisa estar atrelado à apropriação dos meios midiáticos, de modo que cada sujeito possua o conhecimento adequado para a sua utilização. O autor defende que essa apropriação crítica, consciente e criativa demanda um processo de formação, propiciado pela educação formal ou pela formação para o trabalho. Percebe-se que o papel da escola, enquanto instituição educativa, não vem a sucumbir nesse cenário de avanços das tecnologias audiovisuais, mas renova-se e adquire novos contornos, postulando o remodelamento de concepções e práticas pedagógicas para atender às novas exigências sociais desse terceiro milênio. Tal remodelamento deve ser permeado por novas relações com o conhecimento, com a cultura, novas relações com os novos alunos que adentram as instituições de ensino.

Castells (1999) afirma que a educação é o investimento fundamental produtivo para remediar a desigualdade social. O pesquisador pontua que estamos vivendo atrelados ao capitalismo informacional, em que a produtividade e a competitividade envolvem pessoas, regiões, países, imbuídos na tarefa de gerar riquezas, sendo esse um processo flexível e dinâmico que funciona em rede. Diante esse processo, ele defende que deve ser gerado um círculo virtuoso: corrigir a desigualdade e reforçar a produtividade. E acentua que é essencial retomar recursos do processo de criação de riquezas de alta produtividade para redistribuir na educação, pois, segundo ele, isso permite, não apenas corrigir a desigualdade, como, além disso, constitui-se numa força produtiva, pois a maior fonte de produtividade numa sociedade é a capacidade educativa dos indivíduos.

Vislumbrando esse desafio, e buscando imprimir qualidade significativa ao processo de ensino e de aprendizagem, foi forjada a proposta da BNCC (Base Nacional Comum Curricular) que postula e define as aprendizagens fundamentais comuns que os alunos da educação básica no país devem adquirir, o que inclui a apropriação crítica e criativa das mídias digitais à 
disposição em nossa sociedade; inclui aprender sobre elas e através delas. Na estrutura do documento são estabelecidas dez competências gerais para a Educação Básica, que representam os direitos de aprendizagem e de desenvolvimento dos alunos. Evidencia-se, pois, que as demandas tecnológicas, tão importantes no contexto social vigente, emergem de maneira ainda mais contundente, aguçando o olhar investigativo para a necessidade de melhor preparo para os docentes, a fim de que eles estejam aptos e adquiram habilidades básicas para trabalhar na perspectiva da BNCC, de forma crítica e criativa.

Percebe-se que quatro, das dez Competências Gerais definidas, relacionam-se ao acesso à cultura digital e ao uso das tecnologias; o desenvolvimento de competências e habilidades que perpassa todos os componentes curriculares, bem como os respectivos direitos de aprendizagem, está articulado, inexoravelmente, ao uso das TIC's (Tecnologias de Informação e Comunicação).

Nessa mesma direção, Lemes (2018, s/p) enfoca que a educação no estado democrático de direito pressupõe a permanência qualificada na escola para todos, pela equidade e pela justiça, sendo a inclusão seu potencial mais significativo. Para o autor, isso impõe que sejam efetuadas ações e procedimentos para atender em quantidade e qualidade as demandas educacionais. $\mathrm{O}$ autor sublinha que "é fundamental a compreensão adequada das tecnologias atuais, seu potencial de interconexões e seus diferentes papéis no processo de escolarização com equidade". Para ele, essa compreensão envolve conhecimentos e domínios epistemológicos relacionados à tecnologia e à "epistemologia da técnica", exigindo que se retomem, no espaço educacional, as discussões sobre o conhecer e sobre a razão de ser da ação educativa.

Para Levy (1996), o ciberespaço desponta como mediador da inteligência coletiva da humanidade. Os homens constituem-se como seres que realizam múltiplas construções e interações, mediatizados pela linguagem - são seres essencialmente culturais. Diante das mudanças tecnológicas e midiáticas, a cultura adquire outros contornos e não pode deixar de ser enfocada nas relações entre conhecimento escolar, currículo e inovação pedagógica.

Sendo assim, algumas indagações emergem no cenário atual, desestabilizando antigas convicções e premissas: Qual o tipo de escola que queremos? As propostas educacionais estão respondendo de forma satisfatória às exigências das novas gerações? Como atender a tais exigências? Quais são os desafios que se apresentam aos diversos atores envolvidos no cenário educacional? Que competências são necessárias para formar o cidadão do $3^{\circ}$ milênio e os seus professores? Qual o papel da mídia-educação na busca de caminhos para a inovação no contexto educativo e escolar? 
Diante dessas e de outras indagações, o presente trabalho, de cunho bibliográfico, nos limites da sua abrangência, objetiva discutir acerca da necessidade premente de inovações para o cenário educacional e escolar atual, refletindo sobre o papel da mídia-educação e sobre as relações entre conhecimento escolar, cultura e renovação curricular, lançando um olhar panorâmico sobre o papel da mídia-educação na BNCC do ensino fundamental, anos iniciais. Além disso, pretende investigar os desafios que se apresentam para os atores envolvidos nesse cenário, desafios que precisam ser encarados com responsabilidade e comprometimento, uma vez que já não é possível fugir deles. Enfim, é preciso mobilizar esforços e ações conjuntas e articuladas no sentido de propor, como advoga Bizelli (2009, p. 172) “o exercício de uma nova ética que supere a postura fugaz do consumo individual da vida.", sendo imperiosa a necessidade da "criação ética da existência humana, rumo a um mundo multiplataforma que permita a aprendizagem de convivências mais justas e pacíficas".

\section{O contexto educativo e escolar em descompasso com o mundo pós-moderno: a busca de novas relações com o saber, com o aluno, com a cultura, com o currículo escolar}

O contexto educativo e escolar possui uma série de fatores, peculiaridades e aspectos condicionantes imbrincados que constituem uma gama de dinamismo, de complexidade e de antagonismos. Diante desse quadro quase caótico, o principal é consertar o descompasso, não só entre aquilo que a escola ensina e aquilo que o aluno aprende, mas entre o que e como a escola ensina e entre o que e como o aluno da Sociedade da Informação aprende. As mudanças oriundas da cultura digital e suas influências na sociedade são ilustradas sabiamente abaixo:

Em decorrência do avanço e da multiplicação das tecnologias de informação e comunicação e do crescente acesso a elas pela maior disponibilidade de computadores, telefones celulares, tabletes e afins, os estudantes estão dinamicamente inseridos nessa cultura, não somente como consumidores. Os jovens têm se engajado cada vez mais como protagonistas da cultura digital, envolvendo-se diretamente em novas formas de interação multimidiática e multimodal e de atuação social em rede, que se realizam de modo cada vez mais ágil. Por sua vez, essa cultura também apresenta forte apelo emocional e induz ao imediatismo de respostas e à efemeridade das informações, privilegiando análises superficiais e o uso de imagens e formas de expressão mais sintéticas, diferentes dos modos de dizer e argumentar característicos da vida escolar (BRASIL, 2017, p. 59).

O quadro retratado acima elucida o grande desafio que a escola tem diante de si concernente à formação das novas gerações, algo que requer necessariamente novas relações como conhecimento, com a cultura, como o currículo escolar e com os alunos. Levy (1996, s/p) destaca que "um movimento geral de virtualização afeta hoje não apenas a informação e a 
comunicação, mas também os corpos, o funcionamento econômico, os quadros coletivos da sensibilidade ou o exercício da inteligência". Noutros termos, o processo de virtualização transcende os limites pedagógicos, reverberando no âmbito escolar, a visão de mundo e os paradigmas existentes em toda a sociedade.

Sendo assim, é preciso que a escola ressignifique suas concepções epistemológicas, por meio da reconstrução de novas relações com o saber. Disso depende a estruturação e organização do ensino e da aprendizagem. Em tempos de avassaladoras inovações tecnológicas, é sabido que o volume de informações e conhecimentos dobra a cada dois anos. Por outro lado, conhecimentos legitimados pela ciência também sofrem alterações ou perdem sua validade como um constructo inviolável e permanente. Relativizam-se os critérios de verdade; e a enorme variedade de ofertas midiáticas e digitais evidencia que o conhecer é algo dinâmico, flexível. Reconhecer tal situação implica em reestruturar o papel do professor como detentor do conhecimento, e do aluno como aquele que o absorve passivamente. Demanda relações mais verticalizadas de compartilhamento de saberes, de intercâmbios e de compartilhamento de significados entre ambos.

Desde a sua concepção, na Grécia Antiga, até o seu remodelamento como instituição para as massas, no século XIX, a escola esteve atrelada à existência de um "mestre" com saber catedrático que o repassava aos seus alunos aos quais cabia o dever de ouvir e reproduzir com o máximo de fidedignidade possível aquilo que lhe era transmitido, de uma forma passiva e acrítica. A dinâmica pedagógica assentava-se no fator memorístico-cognitivo e mecânico, corroborado pelas concepções tradicionais de ensino e de aprendizagem ao longo dos séculos. Tal modelo ainda prevalece em alguns cenários no contexto brasileiro, a despeito da insurgência de novas teorias e correntes pedagógicas que trouxeram ao campo da pedagogia novos discursos e novas visões, sendo, no entanto, menos impactantes.

Com o advento do Escolanovismo em nosso território, influenciando mudanças na área educacional a partir da década de 1920, as contribuições da psicologia educacional endossaram a abertura de espaço para um novo postulado teórico-metodológico em que o aluno despontava como centro do processo educativo; esse deveria ser direcionado para os seus interesses, motivações, sua pré-disposição para aprender. A partir dessas proposições, são delineadas as chamadas pedagogias ativas ou metodologias ativas, que incluem o Construtivismo e suas vertentes, o Cognitivismo, a Pedagogia de Projetos, a Pedagogia das Competências, do Aprender a Aprender, a Pedagogia Multiculturalista, etc., as quais enfocam o aluno como ser cognoscente, que participa ativamente do processo da construção do seu conhecimento, demandando um processo educacional que prime pela problematização no processo didático, 
pelas inter-relações com o outro, pelo desenvolvimento da autonomia e pela busca ativa e crítica do conhecimento. Essas pedagogias são o fundamento para a busca da inovação pedagógica, pois defendem a superação do modelo tradicional e mecanicista de ensino, sendo também o bojo da Base Nacional Comum Curricular.

A necessidade de novas formas de lidar com o saber está relacionada com a necessidade de novas relações com o aluno, o qual é considerado por Prensky (2001) como um "nativo digital". O termo designa, segundo o autor, o aluno das novas gerações que nasce e convive num contexto social em que é rodeado por recursos e meios tecnológicos, lidando, de modo intensivo, com a linguagem dos computadores, vídeo games e internet. Isso afeta, indubitavelmente, a sua forma de pensar e de processar informações. O problema, posto em relevo pelo autor, é que a maioria dos educadores da atualidade não nasceu no mesmo contexto histórico e social, são "imigrantes digitais", segundo o autor, que precisam aprender como este novo aluno aprende e de que forma interage com o mundo, uma vez que o sistema educacional vigente não foi concebido para esse aluno, que apresenta características diferentes. Sublinha-se ainda que

Os Nativos Digitais estão acostumados a receber informações muito rapidamente. Eles gostam de processar mais de uma coisa por vez e realizar múltiplas tarefas. Eles preferem os seus gráficos antes do texto ao invés do oposto. Eles preferem acesso aleatório (como hipertexto). Eles trabalham melhor quando ligados a uma rede de contatos. Eles têm sucesso com gratificações instantâneas e recompensas frequentes. Eles preferem jogos a trabalhar "sério" (PRENSKY, 2001, s/p).

Sendo assim, é preciso conceber que o estudante da Era Digital aprende e apreende informações de maneira diferente que as gerações anteriores, algo que deixa claro que os métodos de ensino utilizados no passado já não funcionam mais. Bizelli (2009) defende que seja construída uma nova relação com os alunos, os quais devem ser vistos, não apenas como consumidores e usuários de conteúdos digitais, mais como interagentes e interatores. $\mathrm{O}$ autor aborda a relação entre nativos digitais e imigrantes digitais, acentuando que ela deve transcender a noção de risco e ameaça à docência:

[...] os atores comprometidos com o processo pedagógico que se reflete nas relações entre ensino e aprendizagem percebem nas TIC's apenas uma ameaça aos interesses corporativos que protegem os seus fazeres cotidianos. Desorientados e apreensivos sobre o futuro dos seus próprios empregos, querem ser adestrados às ferramentas da inovação sem perceber que, já imersos na Sociedade da Informação, devem procurar outro modelo de se relacionar com seus alunos-interagentes - aqueles que substituíram os alunos espectadores (BIZELLI, 2009, p. 169). 
Isso requer uma reconfiguração do modelo de transmissão de informação, buscando novos modelos que enfoquem a participação do aluno, a autonomia, o livre arbítrio na tomada de decisões, a valorização da interatividade, da conectividade, a criação midiática, incluindo a busca de exercício significativo e crescente da cidadania, por meio, por exemplo, do ciberativismo (ativismo social e político por meio das mídias), da participação crítica e ativa na sociedade como um todo. Assim, minimizar o fosso existente nas relações entre ensino e aprendizagem pressupõe considerar a relação existente entre tecnologia e educação como vetor de novas aprendizagens para educadores e para alunos, como é discutido a seguir por Lemes:

A tecnologia é a epistemologia da técnica em um sentido mais amplo, arte de fazer e fazer implantar. Em outras palavras, a máquina está na dependência da técnica e a partir dela incorporamos conhecimento e aprimoramos a técnica para potencializar as ações. Para que isto dê certo é necessário que educadores acreditem e invistam na sua formação, qualificando-se, e também aprimorem a técnica metodológica de ensino-aprendizagem (2018, s/p).

Por outro prisma, as mudanças na sociedade reiteram a importância de repensar o conceito de cultura, já que a escola é um produto cultural, é produtora e reprodutora de culturas. Esse conceito é muito amplo e multifacetado, de difícil unanimidade entre os estudiosos do tema. Numa acepção antropológica geral, a cultura pode ser vista como tudo aquilo que é produzido pelo ser humano, em oposição à natureza. Essa premissa abarca os objetos, as invenções, as crenças, os hábitos e costumes, os modos de falar, sentir e pensar o mundo, etc. Sendo assim, convém frisar a importância de ratificar o espaço escolar como um ambiente plural, diverso, multicultural, onde se ensina e se aprende sob a ótica do reconhecimento e da valorização das diferenças, sejam elas étnico-raciais, de gênero, de classe social, etc. A partir disso, não há como a cultura escolar permanecer impermeável à cultura digital, uma vez que os seus alunos estão inseridos nela; a instituição escolar precisa incorporar as novas linguagens oriundas das mídias digitais, construindo novas formas de promover a aprendizagem, de interagir com os estudantes e de se relacionar com a cultura digital, considerando que os recursos e as ferramentas tecnológicas, como outros meios, devem estar a serviço de finalidades pedagógicas bem claras e bem delineadas técnica e politicamente.

Para tanto, é necessário retomar as discussões acerca do currículo e do seu papel educativo. Nota-se que há uma variedade de acepções relacionadas ao termo, ressaltando-se aqui o currículo como “[...] toda aprendizagem planejada e guiada pela escola seja ela ministrada em grupos ou individualmente, dentro ou fora da escola" (KELLY, apud LEMES, 2013, p. 175). Lemes (2013) discute o papel do currículo na busca por vias de democratização da escola, defendendo que, para que haja o acesso e permanência qualificada de todos os alunos, 
a escola precisa ser remodelada e o currículo precisa ser reestruturado sob orientações que prevejam a flexibilidade e o multiculturalismo, delineando propostas pedagógicas mais inclusivas e democráticas. Aponta também que

As dificuldades que se apresentam para o currículo, em uma escola democratizada, têm sido ampliadas por entraves vindos de políticas públicas que precisam atender demandas de realidades tão diferentes quanto complexas. Tais demandas avançam em um continuum crescente quantitativa e qualitativamente (p. 176).

Na visão do autor, o currículo deve contemplar as experiências sociais e individuais do estudante, baseando-se numa reflexão sobre a escola e a sociedade, numa perspectiva política e social. Além disso, a adequação, a participação e a flexibilização serão requisitos fundamentais para o currículo numa escola democratizada.

Por outro lado, Prensky (2001) tangencia que os conteúdos escolares devem ser trabalhados em duas perspectivas: o conteúdo "legado" e o conteúdo "futuro". O primeiro diz respeito aos conhecimentos prescritos no currículo tradicional e enfoca habilidades básicas como a leitura, a escrita, a aritmética, o raciocínio lógico-matemático, o conhecimento e compreensão do conteúdo acumulado pelos homens ao longo da história. Para o autor, esses conteúdos são importantes para a formação do aluno, embora a importância de alguns possa ser diminuída com o tempo. Já o conteúdo do “futuro",

inclui software, hardware, robótica, nanotecnologia, genoma, etc. também inclui ética, política, sociologia, línguas e outras coisas que os acompanham. Este conteúdo "Futuro" é extremamente interessante aos alunos de hoje. Mas quantos Imigrantes Digitais estão preparados para ensiná-lo? (PRENSKY, 2001, s/p, grifos do autor).

Por todo o exposto, é notório que há um real descompasso entre o processo linear de transmissão de conhecimento e as novas formas de os alunos se apropriarem do conhecimento na Era Digital, descompasso esse que precisa ser minimizado para tornar a escola um espaço efetivamente democrático.

\section{A educação pelas mídias na Base Nacional Comum Curricular}

É notório que cumpre às instâncias governamentais brasileiras o desafio latente de democratizar, não mais a escola, por meio da ampliação do acesso às instituições escolares, mas democratizar o saber, de acordo com as prerrogativas constitucionais (art. 205 e 206), que preveem que haja a garantia de que as crianças e jovens que adentram os portões escolares de 
fato permaneçam e de fato aprendam aquilo que está previsto para cada ano/série, de acordo com o tempo adequado para isso.

Em face disso, o Estado brasileiro, por meio das diretrizes legais que o orientam (Constituição Federal, 1988; Lei de Diretrizes e Bases da Educação Nacional, Lei 9394/96; Plano Nacional da Educação, Lei 13.005; Diretrizes Curriculares Nacionais da Educação Básica) procura elaborar estratégias para regulação do seu sistema educacional através de políticas públicas voltadas para a área. Essas políticas, traduzidas em forma de programas, de ações ou leis, precisam abarcar e atender as demandas provenientes da pluralidade existente em nosso território, elevando os padrões de qualidade da educação. Diante disso, a Base Nacional Comum Curricular (BNCC) emerge como um conjunto de dispositivos legais que se balizam em princípios éticos, políticos e estéticos, fundamentando-se no arcabouço legal vigente. De modo mais específico,

A Base Nacional Comum Curricular (BNCC) é um documento de caráter normativo que define o conjunto orgânico e progressivo de aprendizagens essenciais que todos os alunos devem desenvolver ao longo das etapas e modalidades da Educação Básica, de modo a que tenham assegurados seus direitos de aprendizagem e desenvolvimento, em conformidade com o que preceitua o Plano Nacional de Educação (PNE) (BRASIL, 2017, p. 7, grifo dos autores).

Não constitui objetivo deste trabalho pontuar críticas ao caráter ideológico da Base, nem apontar possíveis equívocos ou lacunas (obviamente eles existem), mas considerar que, em se tratando de um documento normativo, com rigor legal, os currículos dos sistemas e das redes escolares nacionais deverão ser construídos ou reformulados tendo esta referência, bem como as instituições de ensino deverão reestruturar as suas propostas pedagógicas. Vale ressaltar que, mais do que apenas mudanças administrativas e burocráticas, isso pressupõe uma mudança de olhar, um repensar a educação e o saber-fazer de todos os profissionais envolvidos com ela, um esforço sistêmico, articulado e colaborativo de todos os atores que a constituem. Como parte integrante da Política Nacional da Educação Básica, a BNCC configura-se como um marco inicial e incisivo pela busca de uma educação com maior equidade social para todos os brasileiros, devendo convergir para o alinhamento de outras políticas e ações que subsidiem a sua implementação. Todo esse processo, que certamente será gradual e árduo, demanda mobilização de investimentos, melhoria das ações colaborativas das três esferas do governo, formação continuada dos sujeitos, acompanhamento e avaliação permanente das ações previstas na BNCC e dela decorrentes. Seu cerne é a busca de uma formação integral do aluno que 
assegure "um patamar comum de aprendizagens a todos os estudantes" e contribua para "a construção de uma sociedade justa, democrática e inclusiva" (BRASIL, 2017, p. 7).

Para elucidar a importância da mídia-educação no documento em pauta, convém salientar que, dentre as dez Competências Gerais para a Educação básica (educação infantil, ensino fundamental e ensino médio), quatro tangenciam o uso das mídias digitais/tecnologias para o desenvolvimento dos estudantes, as competências 1, 2, 4 e 5 (BRASIL, 2017, p. 9):

1. Valorizar e utilizar os conhecimentos historicamente construídos sobre o mundo físico, social, cultural e digital para entender e explicar a realidade, continuar aprendendo e colaborar para a construção de uma sociedade justa, democrática e inclusiva.

2. Exercitar a curiosidade intelectual e recorrer à abordagem própria das ciências, incluindo a investigação, a reflexão, a análise crítica, a imaginação e a criatividade, para investigar causas, elaborar e testar hipóteses, formular e resolver problemas e criar soluções (inclusive tecnológicas) com base nos conhecimentos das diferentes áreas.

[...]

4. Utilizar diferentes linguagens - verbal (oral ou visual-motora, como Libras, e escrita), corporal, visual, sonora e digital -, bem como conhecimentos das linguagens artística, matemática e científica, para se expressar e partilhar informações, experiências, ideias e sentimentos em diferentes contextos e produzir sentidos que levem ao entendimento mútuo.

5. Compreender, utilizar e criar tecnologias digitais de informação e comunicação de forma crítica, significativa, reflexiva e ética nas diversas práticas sociais (incluindo as escolares) para se comunicar, acessar e disseminar informações, produzir conhecimentos, resolver problemas e exercer protagonismo e autoria na vida pessoal e coletiva.

Conforme é ressaltado, essas competências deverão ser inter-relacionadas, articuladas e traduzidas na forma de tratamento didático-metodológico no âmbito de todos os componentes curriculares. Na $1^{\text {a }}$ competência, que discorre sobre a importância da valorização e utilização do conhecimento socialmente construído como canal para a compreensão e desvelamento da realidade pelo aluno, o tema da tecnologia aparece, indicando que conhecer o mundo digital é condição para o aluno entender e explicar a realidade, para sua formação ao longo da vida e para que ele contribua "para a construção de uma sociedade justa, democrática e inclusiva". Pela primeira vez, no discurso oficial, as mídias digitais alcançam status de conteúdo, de conhecimento, de objeto de ensino, não apenas de meio e/ou instrumento didático. Na segunda competência, as habilidades ligadas ao uso da tecnologia são pontuadas no campo da investigação científica pelos educandos, relacionando-se com o fomento à curiosidade intelectual, à capacidade de "criar, formular e resolver problemas e criar soluções, de maneira articulada e interdisciplinar". A área das tecnologias, na $4^{\text {a }}$ competência, é enfocada no domínio das linguagens que precisam ser utilizadas pelo aluno para ampliar suas habilidades de se 
comunicar e interagir com o mundo circundante, de compreender o outro e de ser compreendido. A $5^{\text {a }}$ competência, por sua vez, enfatiza o uso crítico, ético, significativo e reflexivo das tecnologias pelo aluno dos diversos contextos e práticas sociais com as mais diversas finalidades, inclusive para exercer a sua cidadania e a sua capacidade de agir no mundo e sobre o mundo de maneira proativa e relevante.

Diante dessas ponderações, percebe-se que as tecnologias têm um valor essencial às práticas educativas do presente século, de modo que o uso adequado das mesmas se torna imprescindível ao exercício da cidadania.

Morin, Ciurana e Motta (2003) sublinham que a ciência moderna e, consequentemente, a escola insistem em dividir e em fragmentar os conhecimentos, enfocando a sua linearidade, compartimentalizando o saber e o ser. Para os autores, há problemas em relação ao método de aprendizagem. Apresentam uma ideia de método, como caminho, ensaio gerativo e estratégia "para" e "do" pensamento. A base desse método seria o trabalho com o pensamento complexo. O termo complexo origina-se do latim e significa "entrelaçar"; "que abraça”, "conjunto". Isso evidencia que, no caminho em busca do conhecimento, não há apenas certezas, determinismos, mas também incertezas, acasos. Sendo assim, o método seria a ação do sujeito pensante que inventa, cria "em" e "durante" o seu caminho. O pensamento complexo engloba a experiência do ensaio como expressão escrita da ação pensante e da reflexão, como forma mais apropriada para a maneira moderna de pensar. Enfim, forjar práticas educativas com base no pensamento complexo pressupõe, inevitavelmente, o uso dos recursos midiáticos dentro de um contexto que faça sentido para os estudantes, que colabore para a sua autonomia individual, emocional, intelectual e social.

Portanto, sabendo que as políticas públicas difundem conhecimento em seu bojo, mas precisam ser retroalimentadas pelos conhecimentos oriundos do "chão" da escola, da sua prática cotidiana, é essencial analisar e ouvir os professores acerca do uso das tecnologias na sala de aula, suas inquietações, dificuldades, propostas já consolidadas, e do modo como os mesmos vão se apropriando (ou não) desses conhecimentos e instrumentos tecnológicos definidos pela BNCC, incorporando-os à sua prática educativa.

\section{Considerações finais}

Diante dos novos desafios apontados pelas novas demandas tecnológicas dessa chamada "era digital" os papéis da escola e do professor se renovam e se revigoram. Embora muitas vezes menos 'treinado' tecnicamente que os próprios alunos em relação ao uso das mídias 
digitais, o professor é aquele que possui (ou deve possuir) o domínio dos saberes e dos recursos didáticos e metodológicos para mediar a construção significativa de conhecimentos e a formação de habilidades, competências e valores imprescindíveis à formação de cidadãos críticos, autônomos e participantes neste novo século e para este novo século. Para tanto, precisa ser preparado e preparar-se, buscando atualização contínua.

Vale frisar que não se pode pensar em aplicar os aparatos e recursos midiáticos dentro de um contexto a-histórico, tradicional de ensino, onde imperam relações verticalizadas entre os sujeitos pois, conforme adverte Lemes $(2018, \mathrm{~s} / \mathrm{p})$, “corre-se o risco de desenvolver recursos midiáticos e colocá-los a serviço de uma escola metodologicamente verbalística, unidirecional, essencialmente reprodutivista e excludente", algo que implicaria em uma incoerência pedagógica, o que significa perda de tempo e de esforços. Inovação educacional e pedagógica não combina com concepções e práticas obsoletas, nem com uma visão tecnicista e reducionista do ensino e da aprendizagem, mas com a formação de cidadãos ativos, críticos, criativos e preparados para o terceiro milênio, pelas vias da democratização midiática. Pérez Gómez ratifica isso quando salienta que

Modernizar a escola, no entanto, não significa simplesmente introduzir equipamentos e infraestruturas que permitam a comunicação em rede. É algo mais do que simplesmente utilizar as novas ferramentas para desenvolver as tarefas antigas de maneira rápida, econômica e eficaz (2015, p. 28).

Essa busca por modernização não pode prescindir de articulação política, esforço do Estado por propiciar as condições técnicas e estruturais necessárias para essa construção. Não se pode deixar de enfocar o papel das instâncias governamentais em zelar pelo processo de formação inicial e continuada dos educadores e profissionais do magistério, forjando políticas públicas que atendam e assegurem as condições básicas para que o uso efetivo e apropriado das tecnologias possa efetuar-se nos espaços escolares. De outra parte, pressupõe que todos os atores envolvidos no âmbito educacional assumam suas responsabilidades para atender adequada e significativamente aos desafios emergidos na Sociedade da Informação. Enfim,

Todo esse quadro impõe à escola desafios ao cumprimento do seu papel em relação à formação das novas gerações. É importante que a instituição escolar preserve seu compromisso de estimular a reflexão e a análise aprofundada e contribua para o desenvolvimento, no estudante, de uma atitude crítica em relação ao conteúdo e à multiplicidade de ofertas midiáticas e digitais. Contudo, também é imprescindível que a escola compreenda e incorpore mais as novas linguagens e seus modos de funcionamento, desvendando possibilidades de comunicação (e também de manipulação), e que eduque para usos mais democráticos das tecnologias e para uma participação mais consciente na cultura digital. Ao aproveitar o potencial de comunicação do 
universo digital, a escola pode instituir novos modos de promover a aprendizagem, a interação e o compartilhamento de significados entre professores e estudantes (BRASIL, 2018, p. 59)

Em suma, repensar, pois, o papel da escola e do professor é pensar no remodelamento da sua didática para se adequar e atender às novas exigências sociais do seu público-alvo. Inovação demanda esforço rumo à reflexão e à ação. Um novo jeito de sentir, pensar e fazer o ensinar e o aprender, assentando-se, pois, sobre novas concepções de conhecimento, de relacionamento professor/aluno, de cultura, de currículo escolar. Apenas novas concepções chancelam e consolidam práticas inovadoras.

\section{REFERÊNCIAS}

BIZELLI, José Luis. Inovação, limites e possibilidades para aprender na era do conhecimento. São Paulo: Cultura Acadêmica, 2013.

BRASIL. Base Nacional Comum Curricular: Educação Infantil e Ensino Fundamental. Brasília: MEC/Secretaria de Educação Básica, 2017.

CASTELLS, Manuel. A sociedade em rede. São Paulo: Paz e Terra, 1999.

LEMES, Sebastião de Souza. O currículo para a escola democratizada: das pistas históricas às perspectivas necessárias. In: Cadernos de Formação - Formação de professores.

PROGRAD/UNESP, São Paulo: Cultura Acadêmica, 2013.

LEVY, Pierre. O que é virtual? São Paulo: Ed. 34, 1996. 157p.

MORIN, Edgar; CIURANA, Emílio Roger; MOTTA, Raul Domingo. Educar na Era Planetária: $O$ pensamento complexo como método de aprendizagem no erro e na incerteza humana. Tradução: Sandra Trabucco Valenzuela. São Paulo: Cortez, 2003.

PÉREZ GÓMES, Ángel. I. Educação na era digital: a escola educativa. Tradução Marisa Guedes; revisão técnica: Bartira Costa Neves. Porto Alegre: Penso, 2015.

PRENSKY, Marc. Nativos digitais, imigrantes digitais. Tradução de Roberta de Moraes Jesus de Souza. De On the Horizon. NCB University Press, v. 9, n. 5, out. 2001. 


\section{Como referenciar este artigo}

ROCHA, Rosineide de Andrade; FISCARELLI, Sílvio Henrique; RODRIGUES, Rodolfo Augusto. Caminhos para a inovação no contexto educativo e escolar: o papel da mídiaeducação. Revista on line de Política e Gestão Educacional, Araraquara, v. 24, n. 1, p. 270284, jan./abr., 2020. e-ISSN:1519-9029. DOI: https://doi.org/10.22633/rpge.v24i1.13422

Submetido em: 20/06/2019

Revisões requeridas: 30/08/2019

Aprovado em: 25/10/2019

Publicado em: 06/01/2020 